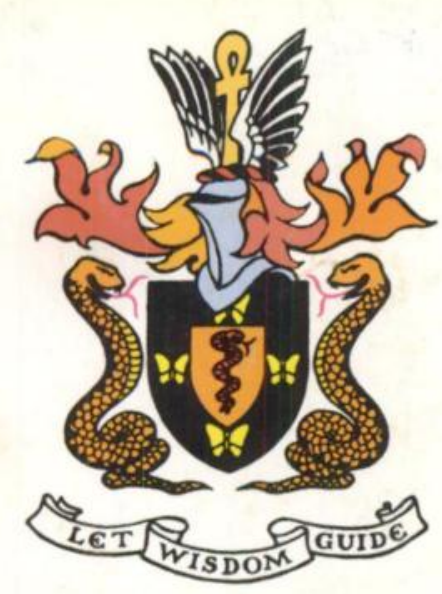

THE BRITISH JOURNAL OF PSYCHIATRY March 1992

Vol. 160

Annotation

Seeing is believing: the role of 'preconscious' perceptual processing in delusional misidentification. $S$. Fleminger

\section{Point of View}

Research on symptoms versus research on syndromes. Arguments in favour of allocating more research time to the study of symptoms. C. G. Costello

\section{Review Articles}

Drug therapy of post-traumatic stress disorder. J. Davidson

New treatments for erectile impotence. $A$. Gregoire

\section{Papers}

The manufacture of personalities. The production of multiple personality disorder. H. Mersky

Pica: symptom or eating disorder? A historical assessment. B. Parry-Jones and W. Ll. Parry-Jones

Who benefits from electroconvulsive therapy? Combined results of the Leicester and Northwick Park trials. H. Buchan, E. Johnstone, K. McPherson, R. L. Palmer, T. J. Crow and S. Brandon
Is old-fashioned electroconvulsive therapy more efficacious? A randomised comparative study of bilateral brief-pulse and bilateral sine-wave treatments. A. I. F. Scott, C. R. Rodger, R. H. Stocks and A. P. Shering

Timing of acute clinical response to fluphenazine. D. F. Levinson, $H$. Singh and G. M. Simpson

Decreased 5-HT-mediated prolactin release in major depression. I. M. Anderson, C.J.Ware, J. M. da Roza Davis and P. J. Cowen

The Daily Living Programme. Preliminary comparison of community versus hospitalbased treatment for the seriously mentally ill facing emergency admission. M. Muijen, I. M. Marks, J. Connolly, B. Audini and G. McNamee

315 Factor analysis of the Level of Expressed Emotion Scale, a questionnaire intended to measure 'perceived expressed emotion'. $C$. Gerlsma, P. M. van der Lubbe and C. van Nieuwenhuizen

The brain damage hypothesis of the seasonality of births in schizophrenia and major affective disorders: evidence from computerised tomography. E. Sacchetti, A. Calzeroni, A. Vita, A. Terzi, F. Pollastro and C. L. Cazzullo

Brief Reports

A study of suicide in schizophrenic in-patients.

Continued inside

\title{
MAR 161992
}

\section{PSTCRATRIC CLRE AEW YORK WOSPRAL}

$$
\begin{aligned}
& \text { Nat to be bitse } \\
& \text { from Liverary }
\end{aligned}
$$

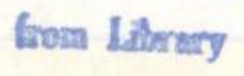$$
\text { chiatrists }
$$

ISSN $0007-1250$ 


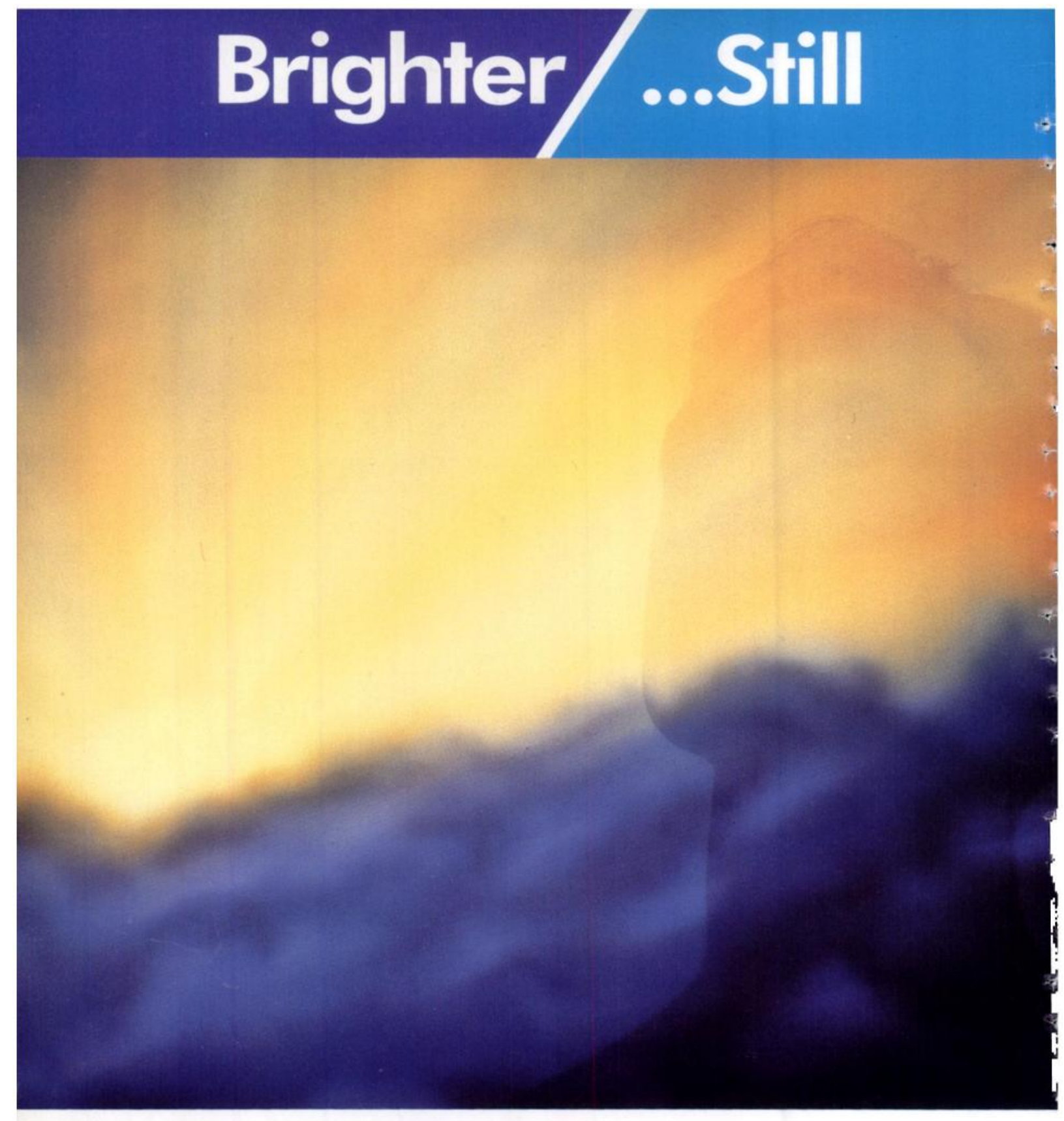

\section{DFFOT IIIII NEW LVOPTION. DEPIXØ $L^{\circ}$ cis(Z)-flupenthixol decanoate}

\section{LIFTING MOODS, CALMING PSYCHOSES}

Further information is available from: LUNDBECK LIMITED, Lundbeck House, Hastings Street, LUTON, Beds. LUI 5BE 